\title{
The Effectiveness of a Suggested Specific Course on Developing Third-year University Students' Skills in Translating Culture-specific Items
}

\author{
Montasser Mohamed Abdelwahab Mahmoud \\ College of Languages and Translation, Al-Imam Muhammad Bin Saud Islamic University, Saudi Arabia
}

\begin{abstract}
This study aimed at helping students to deal systematically and effectively with culture-specific items. This was treated through designing and applying a specific course based on sixteen strategies adopted from what Newmark(1988), Hariyanto (1997), and Harvey (2003) suggested. The course was designed in the light of these strategies. It included different cultural topics with various cultural items in both English and Arabic. The course was applied in seven weeks to a sample of third-year university students at Al-Imam Muhammad Bin Saud Islamic University, College of Languages and Translation, during the first seven weeks of the second term. Students were asked to answer a pre-test on culture-specific items. The same test was distributed on students after the treatment which was represented in teaching the specific course. A Wilcoxon test was used to compare students' scores in each item and in the test as a whole. The results showed the effectiveness of using the specific course in developing third-year students' skills in translating culture-specific items. However, the change that happened for students was not very high as only one got an excellent degree and just four got a very good degree. The percentage of unsuccessful students reached $25 \%$ and the percentage of students with fair degree reached $40 \%$. This reflected the fact that the time was not enough as students needed more practice. In general, strategy teaching is very important but it is not sufficient to create professional or good translators.
\end{abstract}

Index Terms - culture-specific items, translation strategies, specific course

\section{INTRODUCTION}

In recent translation studies, special attention has been paid to the examination of cultural aspects. Rabin (1972) believed that translators tended to make certain decisions before starting translation. Such decisions were conditioned not only by the translators' linguistic competence but also by their cultural background. In other words, the way translators understand and appreciate the source culture is one of the factors that influence the way in which they translate. Hermans (1999) asserted that that translation should be recognized as a cultural practice. Gerding-Salas (2000) stated that translation is considered a cross-cultural bilingual communication vehicle among people of different tongues and cultures by attempting to interpret concepts and speech in a variety of texts as faithfully and accurately as possible. Moreover, Pena, (2007) affirmed the importance of cultural equivalence in the process of translation. Bahameed (2008) underscored the role played by intercultural translation in modern social linguistics theories. Such views pinpointed that both language and culture should be highly regarded in the act of translation. However, cultural differences may cause more serious translation problems than do linguistic differences.

It is a very hard task to translate the cultural aspects of any source language as the reader of a particular culture will expect the translation to be associated his customs and beliefs with expressions derived from his culture because the people of a given culture look at things from their own perspectives (Lefevere, 1992). Thus, the translator needs to be aware of the use of such expressions since translation is affected by the kind of society from and to which it is performed (Larson, 1984). Any cultural term is the result of the behavior of a certain society and in translation this cannot be easily conveyed. Sometimes both the source and the target language have cultural equivalents or correspondences but the problem arises when there is a cultural gap between the two concerned languages. Newmark (2001) saw culture as the greatest obstacle to translation, at least to the achievement of an accurate and decent translation (p.328). Armellino (2008) considered translating culture-bound elements of a source language into a target language the most challenging tasks for all translators. He believed that replacing culturally-bound words or phrases in one language by the same words or phrases in another language is often impossible because the meaning is always linked to the specific cultural context where the text originates or with the cultural context it aims to recreate.

Previous Research

Aly (1990) designed a translation course for the students of English at faculties of education. Al-Maghraby (1995) developed some guidelines for building translation courses. Solhy (2002) evaluated the current state of teaching translation in the Arab universities and suggested a comprehensive systematic program for designing translation courses. Dadour (2004) proposed a translation program for developing EFL prospective teachers' bicultural awareness and performance in translation. Al-Hasnaw (2007) investigated the 'untranslatability' of some Arabic metaphors into English 
and found that most metaphors are shaped by the socio-cultural beliefs and attitudes of a specific culture. Zare-Behtash (2010) discussed culture-specific items in literary texts.

In the light of the aforementioned review, culture-specific items and translation strategies can be conceptualized as unique elements to a language that cannot be understood simply from the meaning of their individual words but they require an adequate cultural awareness of both the source language and the target language cultures. Moreover, the aforementioned review revealed two important remarks. Initially, most of the foreign translation studies focused on translation as a process, while many Arabic studies focused on translation as a product. Furthermore, the role of culture in translation is marginalized in the previous research especially in the Arab world. This means that more studies are needed in the area of culture and translation. This paper attempted to focus on translation as a process as well as a product. It concentrated on the process of translation through teaching a theoretical part related to the strategies that students could use to overcome the problems of translating culture-specific items and noticing the way students usually resort to while translating. It also gave great attention to the product that students gave either in their translation of the cultural texts involved in the specific course or in the outcome of the assignments given to them every week and discussed later in next classes. This study was also different from the previous studies in its focus on both kinds of translation; from English into Arabic and vice versa.

\section{Review of Literature}

As for translation strategy that could be used to overcome the problem of translating culture-specific Items, literature on several translation strategies showed how they were taken into account by some linguists. Newmark (1988) suggested a long list of translation strategies that could be used such as: naturalization, cultural equivalent, functional equivalent, descriptive equivalent, componential analysis, synonymy, shift, transposition, modulation, recognized translation, compensation, paraphrase, couplets, and notes. Hariyanto (1997) suggested some strategies for translating cultural aspects such as: addition, componential analysis, cultural equivalent, descriptive equivalent, literal translation, modulation, recognized translation, reduction, synonymy, transference, deletion, and combination. Moreover, Harvey (2003) suggested four strategies for translating culture bound idioms such as: functional equivalence, formal equivalence or linguistic equivalence, transcription or borrowing, and descriptive or self-explanatory. This study used sixteen strategies adopted from what Newmark (1988), Hariyanto (1997), and Harvey (2003) suggested. They were taught to students within seven weeks, three hours a week.

\section{Statuesque of Teaching Translation at University Level}

It seems that many undergraduate students come to university with the aim of gaining a qualification because that is the best way to get a prominent job. The actual usefulness or relevance of what is learnt to future employment is not a question that is often asked. Thus it seems that what is learnt in the classroom is not expected to be relevant to real-life work. The method of teaching is often very teacher-centered, and students expect to take notes which they then learn in order to reproduce in the exam. There is no real engagement of the critical faculties of the brain. Hence, professors and lectures are authority figures whose word is law and who must not be embarrassed by questions.

Unfortunately, even worse, the majority of the students regard translation as a minor subject compared with poetry, the novel, or drama. Since the class does not have textbooks, or even handouts, they assume that there is nothing to study, and all they have to do is learn vocabulary by heart and just attend and write down whatever translations the professors and lectures may dictate. Worst of all, many of them apply the rule of 'parroting' (Larson, 1984), in other words, they learn by heart whatever translations the teacher may propose. (p.11)

In such a case, class participation is undermined because only more proficient and confident students can interact with the student/teacher and engage in discussion. Taking these previous notes into consideration and hoping to make a kind of change in the course as well as the method of teaching translation, the researcher attempted to offer something new and creative by designing a specific course that could allow students to be active participant and creative in the process of translation.

\section{Statement of the Problem}

Translating culture-specific items is expected to be one of the most nagging translation problems facing EFL learners at Al Imam Muhammad Bin Saud Islamic University. To be more specific, this study was concerned with teaching a specific course that included strategies for translating culture- specific items accompanied with different kinds of cultural texts so as to help EFL Saudi students translate culture-specific items involved in these texts. To better study the problem under investigation, the following two research questions were raised:

1. What is the effectiveness of using specific course in cultural translation for developing students' skills to translate culture-specific items?

2. What are the most effective strategies that helped students overcome their problems in translating culture-specific items?

\section{Hypotheses of the Study}

1. There is a statistically significant difference between the mean scores of the students on the pre-test and the posttest concerning the first item of questions in favor of the post- test.

2. There is a statistically significant difference between the mean scores of the students the pre-test and the post- test concerning the second item of questions in favor of the post- test. 
3. There is a statistically significant difference between the mean scores of the students the pre-test and the post- test concerning the third item of questions in favor of the post- test.

4. There is a statistically significant difference between the mean scores of the students the pre-test and the post- test concerning the fourth type of questions in favor of the post- test.

5. There is a statistically significant difference between the mean scores of the students the pre-test and the post- test concerning the whole items of questions in favor of the post- test.

Objectives of the Study

The study tried to achieve the following objectives:

1. To investigate the effectiveness of using a specific course in cultural translation for developing students' skills to translate culture-specific items.

2. To identify the most effective strategy that helped students overcome their problems in translating culture-specific items.

3. To develop a culture-based translation course.

4. To develop a culture-based translation test.

5. To develop a translation strategy awareness among students.

\section{Methodology}

\section{A. Participants}

The current study targeted the third year English language male majors at the University of Imam Muhammad Bin Saud Islamic University. The study participants involved all the EFL Saudi students who were performing their final term exams of the second semester of the academic year 2012/2013. The participants were (43) EFL students whose age was ranging from 21 to 23 years old. The sample was limited to the third year English language majors who are supposed to be well acquainted with English language and translation courses.

\section{B. Instruments}

\section{Culture-Based Translation Course}

As far as designing translation course is concerned, there must be a sort of balance between theory and practice although it is preferred to lean a little bit on practice, because it is practice that actually produces a good translator (Samudra, 1993). Accordingly, the researcher selected to design this specific course in such a way that helps students enjoy and practice translating as much as possible. (p.53) The researcher designed the specific course and sent it by email to his colleagues to check it and give him their feedback. Their suggestions and comments were most welcome and significant. The researcher used such points to modify and improve the final version of the course. Continuous evaluation and feedback were always given during the process of teaching the course. Students were often asked to give their frank opinion concerning the course. The benefits of the course were weighed carefully to figure out if the course truly helped effectively developed students' skills in translating culture-specific items or not. Colleagues and students were always queried about every aspect of the course: How long does it take? What kind of strategy do students learn better? Are the topics related closely to the main objective of the course? Does the coursework reflect students' interests and give them the training they need to succeed in translating cultural texts in general and culture-specific items in particular?

In designing the course, the researcher tried to avoid the errors that could be made by any course designer such as the overload of information presented in the course and the unsuitability of the time allotted for teaching the course. Students were given enough time to learn and practice the new strategies. The course was not too brief or too shallow. It was deep enough to arouse students' motivation and satisfy their needs. Immediate correction was provided and discussion of certain issues was allowed. The topics involved in the course matched the skills and experience of the students and

\subsection{Course Objectives}

The Objectives of the Course are Included the Following Points:

1). Enhancing basic skills in cultural translation.

2). Intensive training in the translation of culture-specific items from Arabic into English and vice versa.

3). Training the students to acquire the skills of using various translational strategies to overcome problems they face in cultural translation.

4). Developing the student's insight into the strategies of translating culture-specific items.

5). Offering a systematic syllabus that could develop students' skills in translating culture- specific items.

6). Giving students more chances to have constructive dialogue and exchange of ideas and experiences concerning the translation of culture-specific items.

7). Promoting the student's competence in the mother tongue and the foreign language.

8). Stimulating an intellectual and linguistic challenge in the student.

9). Training students to be future translators by teaching them real-life work translations.

10). Giving students a chance to read about different aspects of foreign as well as local cultures.

\subsection{Teaching Methods:}


1) Lectures

2) Class discussions; encouraging class participation and presentations

3) power point presentations (visual aids)

4) giving handouts

5) tutorials, group discussion and team work

\subsection{Learning Methods}

1) The use of the internet.

2) Keeping journals and files for new terms and collocations students learn.

3) Submitting home assignments regularly in well-organized files.

4) Correcting each others' translation and language mistakes through displaying their assignments in the class.

\subsection{Cultural Topics}

The topics included in this specific course were carefully selected to meet the needs of students to overcome the problem of translating culture- specific items. The course was designed to be applied in seven weeks. The material of the course was taught three hours a week and was distributed as follows;

\subsubsection{Week 1}

1. A pre- test was given to students to investigate the effectiveness of using this specific course in developing students' skills concerning translating course- specific terms.

2. An introduction to the course, showing the main points that students were going to study in this specific course, was explained to students.

\subsubsection{Week 2}

1. Revision of the differences between the literal, free, semantic and communicative approaches to translation.

2. A Handout containing short texts with their translations was given to students; it was used as a tool to help students recognize how approaches of translation are used.

\subsubsection{Week 3}

1). General Discussion on the different kinds of strategies used to translate culture-specific items was made.

2). A handout containing explanation, illustration and examples of the first four strategies (cultural equivalentscultural correspondence- accepted standard translation- naturalization) that could be used to translate culture-specific items was distributed on the students.

3). Two cultural texts were given to students to apply and practice the use of the four strategies; one to be done in class and the other to be taken as an assignment.

4). A power point presentation containing important information about the culture specific items included in the class-done text was offered. This information was presented in the form of short passages that helped students a lot to acquire much experience about features of foreign cultures as well as some aspects of their own culture. It played a vital role in enhancing students' translation skills concerning culture-specific items.

5). Another power point presentation containing true-false questions was provided to students to get their comments.

\subsubsection{Weeks 4}

1). A handout containing explanation, illustration and examples of other four strategies (general sense - transcription - literal translation - translation couplets), that could be used to translate culture-specific items, was given to students.

2). Two cultural texts were given to students to apply and practice the use of the four strategies; one to be done in class and the other to be taken as an assignment.

3). A power point presentation containing important information about the culture specific items included in the class-done text was offered. This information was presented in the form of short passages that helped students a lot to acquire much experience about features of foreign cultures as well as some aspects of their own culture. It played a vital role in enhancing students' translation skills concerning culture-specific items.

4). Another power point presentation containing short sentences with their translations was offered. Each sentence has one underlined culture-specific item that has been translated using a certain strategy. Based on the strategies they have studied, students were asked to determine which strategy has been used.

\subsubsection{Week 5}

1). A handout containing explanation, illustration and examples of other four strategies (translation triplet - classifier - neutralization - componential analysis) was given to students.

2). Two cultural texts were given to students to apply and practice the use of the four strategies; one to be done in class and the other to be taken as an assignment.

3). A power point presentation containing important information about the culture specific items included in the class-done text was offered. This information was presented in the form of short passages that helped students a lot to acquire much experience about features of foreign cultures as well as some aspects of their own culture. It played a vital role in enhancing students' translation skills concerning culture-specific items.

4). Another power point presentation containing short sentences with their translations was offered. Each sentence had one underlined culture-specific item that had been translated using a certain strategy. Four choices were provided after each translation and students were asked to select the correct answer.

\subsubsection{Week 6}


1). A handout containing explanation, illustration and examples of other four strategies (paraphrase - translation label - deletion - gloss, notes, and footnotes) was given to students.

2). Two cultural texts were given to students to apply and practice the use of the four strategies; one to be done in class and the other to be taken as an assignment.

3). A power point presentation containing important information about the culture specific items included in the class-done text was offered. This information was presented in the form of short passages that helped students a lot to acquire much experience about features of foreign cultures as well as some aspects of their own culture. It played a vital role in enhancing students' translation skills concerning culture-specific items.

4). Another power point presentation containing short sentences with their translations was offered. Each sentence had one underlined culture-specific item that students had to translate using one of the strategies they studied in the course. A good discussion was raised among students as each one wanted to use a certain strategy. They gave the researcher a good impression about the development that happened concerning their awareness of translation strategies.

\subsubsection{Week 7}

1). General revision was made on the whole strategies. The main focus was on the differences between these strategies and the order of their preference. Students were asked to give the difference with examples.

2). A post- test was distributed on the students to investigate the efficiency of the specific course in developing students' skills in translating culture-specific items.

\subsection{Assignments}

In essence, the translation course depended on giving students plenty of time to do translation assignments, then analyzing those assignments in every detail, and ultimately discussing the nature of their work, often with an extreme focus on student errors, in great depth. Besides, students were introduced to the purpose and nature of translation. According to Newmark (1988): "What translation theory does is, first to identify and define a translation problem; second, to indicate all the factors that have to be taken into account in solving the problem; third, to list all the possible translation procedures; finally, to recommend the most suitable translation procedure, plus the appropriate translation."(p.9)

Assignments were given each week to students. They were asked to do it at home. Sometimes students complained that the assignment contained some difficult parts. It was something normal especially when translating cultural texts. The tool of discussion was used to overcome any problems concerning translating culture-specific items. At the first stage the difficulty of finding no equivalent was their main problem but gradually they acquired the ability to deal with such a problem by using different types of strategies they had studied in the course.

\section{Culture-Based Translation Test}

The main objective of the test was to investigate the effectiveness of using this specific course in developing students' skills in translating culture-specific terms. To determine the raw content of the test, the researcher reviewed the related literature and previous research to list the most important strategies that should be included in the test through using phrases or short texts and asking students to translate them from English into Arabic and vice versa. The students were also asked to determine the strategy that they used to translate the culture- specific items included in the phrases as well as in the texts.

\subsection{Layout of the Test}

As for the layout of the test, it was taken into consideration that the content of the test be clear and allows the testtakers to respond easily. Each test phrase contained one culture-specific item while the short texts contained more than one item. The students were asked to translate each item into a full meaningful item. The test consisted of ten Arabic phrase, ten Arabic short texts, ten English phrases and ten English short texts. The students were asked to give the right equivalent in the Target Language, and to determine the strategy they used to translate such culture-specific items.

\subsection{Validity and Reliability of the Test}

For assessing the validity and reliability of the test, the test was reviewed by the same EFL experts who approved its face and content validity. For estimating the reliability of the test, the test was administered twice. At the end of the first semester on the 9th of January 2013, the test was administered to 9 Saudi university English language majors at the University of Imam Muhammad Bin Saud Islamic University. After a week on the $16^{\text {th }}$ of January, the test was readministered to the same students. The test-retest procedure was used to calculate the reliability of the test using Pearson product-moment correlation coefficient. The reliability coefficient of the test was $(r=0.78)$.

\subsection{Administration of the Test}

The test was administered on Saturday the 26th of Jan. 2013 at the University of Imam Muhammad Bin Saud Islamic University in the second semester of the academic year 2012/2013. The pre- test was given to the students on the first week of study in the second semester and the post-test was given to them on the seventh week of study. The students were informed that that this test would not affect their academic performance or scores. It was made clear that the test is a part of an academic study. After finishing the test, students' responses were collected. The time allotted for the test was one hundred minute.

\subsection{Scoring the Test}

The total score of the test was (60) scores where one point was devoted to translating the phrase and two points were devoted to translating each short text. Exact or accurate cultural translation of the phrase was given one point, while half 
a point was given to any acceptable translation. As for the translation of the short texts, two points were given to accurate translation, while one point was devoted to any acceptable translation. Literal or inaccurate translation was scored zero. Students' scores were interpreted according to five criteria; less than $60 \%$ means poor, from $60 \%$ to $69 \%$ means fair, from $70 \%$ to $79 \%$ means good, from $80 \%$ to $89 \%$ means very good, and from $90 \%$ to $100 \%$ means excellent.

\section{RESULTS AND DISCUSSION}

It was clearly noticed during teaching this specific course that students felt happy when they translated cultural terms as they were shown how these terms could be carried into the Target Language safely and satisfactorily. They believed that they could acquire invaluable knowledge of the cross- and different aspects of the Source Language and Target Language cultures, and they could bridge many cultural gaps between the Source and the Target Language cultures through refining and develop their translation skills at dealing with cultural terms in translation. The test was divided into four sections; two of them were devoted for translating from English into Arabic while the other two were for translating from Arabic into English. Students were asked in each type of translation to translate culture-specific items included in short texts as well as items alone without been found in any context. The following table showed the total results on the test:

TABLE 1:

PARTICIPANTS' TOTAL RESUlTS ON THE POST- CBTT

\begin{tabular}{|l|l|l|} 
PARTICIPANTS' TOTAL RESULTS ON THE POST- CBTT \\
\begin{tabular}{|l|l|l|}
\hline Participants & Pass & Fail \\
\hline 40 & $30(75 \%)$ & $10(25 \%)$ \\
\hline
\end{tabular}
\end{tabular}

This result meant that the participants managed to achieve the required mean scores. Accordingly, EFL students were able to translate culture-bound expressions with very good degree $(75 \%)$. It was clear that while third-quarter of the participants could pass the test, $25 \%$ of the participants $(n=10)$ could not pass the test. This confirms the conclusion that the specific course was to a good extent helpful for students to get better marks in the post test. To be more specific and exact, the following table showed the number and the percentage of the participants with regard to degrees of evaluation.

TABLE 2:

PARTICIPANTS' DETAILED RESUlTS ON THE POST CBTT

\begin{tabular}{|l|l|l|}
\hline Criteria & Number & Percentage \\
\hline Fail & 10 & $25 \%$ \\
\hline Fair & 14 & $35 \%$ \\
\hline Good & 10 & $25 \%$ \\
\hline Very Good & 5 & $12.5 \%$ \\
\hline Excellent & 1 & $2.5 \%$ \\
\hline
\end{tabular}

For further evidence, table (2) showed that only one student could reach the degree of excellence in his translation while five students $(12.5 \%)$ managed to reach the level of very good degree. This revealed that culture-specific items were not easy to translate even if the students were subject to studying specific strategies to deal with. On the other hand, it cannot be denied that the specific course with its strategies was helpful to some students as the results included in this table revealed; ten students (25\%) got good degree while fourteen (35\%). got fair degree.

\section{As for the First Hypothesis}

In order to verify the validity of this hypothesis, a Wilcoxon Signed Ranks Test was used to compare the mean scores of the students' answers on the pre/post- test. The results proved to be statistically consistent with the hypothesis. See table (32).

TABLE:3

A Wilcoxon Test Results Comparing the Pre- Test vs. Post- Test MeAns For the Students IN the FiRSt Item of Questions

\begin{tabular}{|l|l|l|l|l|l|}
\hline & N & Mean & Std. Deviation & Minimum & Maximum \\
\hline Pre & 40 & 3.450 & 1.3436 & 1.0 & 6.0 \\
Post & 40 & 6.788 & 1.4715 & 4.0 & 9.5 \\
\hline
\end{tabular}

Table (3) indicated that there was a statistically significant difference at 0.00 level in the first item of questions between the mean scores of the students on the pre-test (3.450) and the post-test (6.788) in favor of the post-test since the estimated z- value was(-5.558). Thus, it can be safely said that the Wilcoxon test results proved to be statistically consistent with the hypothesis. Therefore, the first hypothesis was confirmed. In addition, the estimated $\mathrm{Z}$ value indicated that the specific course had a large effect on the students' performance concerning the first item of questions on the post- test as compared to their results on the same item on the pre- test. The minimum degree obtained by students on the pre-test was one out of ten while the minimum degree obtained by students on the post-test was four. The same growth was noticeable in students' maximum degree on the pre and post-test. As for the pre-test, the maximum was six while on the post-test, it was 9.5. this revealed the development that happened in the students' 
performance in translating the sentences included in the first item of questions. This is, of course, due to the use of the specific course that included definite strategies in translating culture-specific items.

\section{The second Hypothesis}

To determine the relative extent of change fostered by the implementation of the proposed specific course from the pre-test to the post-test for the students, a Wilcoxon test was used. This test aimed at comparing the mean scores of the students group on the pre- test and the post- test in overall questions included in the second item. See table (4).

TABLE:4

A Wilcoxon Test Results Comparing the Pre- Test vs. Post- TeSt Means For the Students in the Second Item of Questions

\begin{tabular}{|l|l|l|l|l|l|l|}
\hline & N & Mean & Std. Deviation & Minimum & Maximum \\
\hline Pre & 40 & 1.688 & .9916 & .0 & 4.0 & -5.570 \\
Post & 40 & 4.625 & 1.0786 & 2.5 & 7.0 \\
\hline
\end{tabular}

Table (4) indicated that there was a statistically significant difference at 0.00 level in overall questions in the second item between the mean scores of the students on the pre-test(1.688) and the post-test (4.625) in favor of the post-test since the estimated Z- value was(-5.570). Thus, it could be safely said that the Z-test results proved to be statistically consistent with the hypothesis. Therefore, the second hypothesis was confirmed. In addition, the estimated $\mathrm{Z}$ value(3.26) indicated that the specific course had a large effect on the experimental group students' overall questions in the second item on the post- test as compared to their results on the pre- test. The minimum degree in the pre-test was zero but it rose to be 2.5 in the post-test. The same applied to the maximum degree as it rose from four degree to reach seven. It was noticed that the degree of maximum did not grow much as most students were not able to give the correct translation. This might due to the difficulty of most cultural items as well as the unfamiliarity of the students with such items. They did their best to give an appropriate equivalent but the context did not help them reach their goals.

\section{The Third Hypothesis}

In order to verify the validity of this hypothesis, a Wilcoxon test was used. The results proved that there were statistically significant differences between the mean scores of the students on the pre-test and the post-test in overall literal, inferential, and critical comprehension levels and their sub- skills. In other words, the results of the t- tests proved to be statistically consistent with the above stated hypothesis. Therefore, the ninth hypothesis was accepted. The following tables show this statistical significance.

TABLE:5

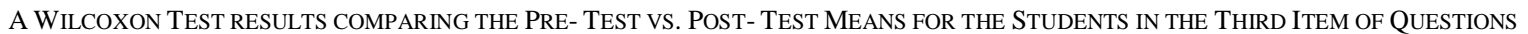

\begin{tabular}{|l|l|l|l|l|l|l|}
\hline & N & Mean & Std. Deviation & Minimum & Maximum \\
\hline Pre & 40 & 3.9250 & 1.26364 & 1.00 & 6.00 & -5.482 \\
Post & 40 & 7.100 & 1.3737 & 4.0 & 9.0 & \\
\hline
\end{tabular}

Table (5) showed that there was a statistically significant difference at 0.00 level between the mean scores of the experimental group on the pre-test and the post-test in overall questions of the third item ( $Z$ value $=\mathbf{- 5 . 4 8 2})$ in favor of the post- test. In addition, the results shown in the above table revealed that the proposed specific course had a large effect on developing students' overall translation skills with regard to culture-specific items as shown in their performance on the post- test compared to their results on the pre- test. The minimum changed from one to become four in the post test while the maximum rose from six to nine. These results revealed the existence of statistically significant differences at 0.00 levels in this respect.

\section{The Fourth Hypothesis}

To determine the relative extent of change fostered by the implementation of the proposed specific course from the pre- test until the post- test for the students in all questions of the fourth type, a Wilcoxon test was used. was used. The following table shows the existence of a statistically significant difference at 0.00 level.

TABLE:6

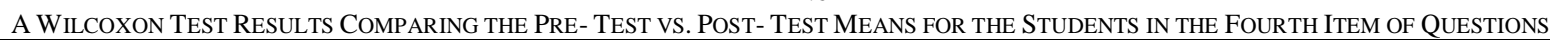

\begin{tabular}{|l|l|l|l|l|l|}
\hline & $\mathbf{N}$ & Mean & Std. Deviation & Minimum & Maximum \\
\hline Pre & 40 & 1.662 & .7876 & .0 & 4.0 \\
Post & 40 & 4.638 & 1.0977 & 1.0 & 6.5 \\
\hline
\end{tabular}

Table (6) showed that there was a statistically significant difference at 0.00 level between the mean scores of the students on the pre-test (1.662) and the post-test (4.638) in favor of the post-test scores in all questions included in the fourth item. In addition, the $\mathrm{Z}$ value (-5.548) revealed that the proposed specific course had an effect on developing the students' skills concerning translating culture-specific items as shown in their performance on the post- test compared to their performance on the pre- test. The effect was not high concerning this item as the culture-specific items included in the questions of this item were difficult and unfamiliar to students so the minimum just reached one and the maximum changed from four to 6.5 . 
To further investigate the differences between the students' performance before and after being exposed to the specific course, a Wilcoxon test was used. The following table showed the existence of statistically significant differences at 0.00 level.

TABLE:7

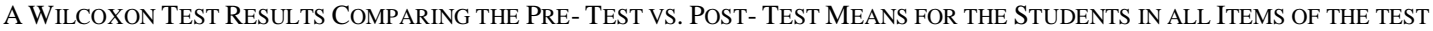

\begin{tabular}{|l|l|l|l|l|l|l|}
\hline & N & Mean & Std. Deviation & Minimum & Maximum \\
\hline Pre & 40 & 10.725 & 3.8480 & 3.0 & 19.0 \\
Post & 40 & 23.150 & 4.1867 & 16.0 & 32.0 \\
\hline
\end{tabular}

As shown in the above table, the estimated Z- values (-5.517) revealed that there was statistically significant difference at 0.00 level in favor of the post- test. Moreover, the results proved that the proposed specific course had a large effect on developing the students' skills in translating culture-specific items on the post- test as compared to the pre- test.

In sum, the present study was conducted to measure the effect of a specific course on developing students' basic skills in translating culture-specific items. Results of the study confirmed that there was a remarkable increase in students' level of achievement after the experiment. Means of scores in the posttest and the obtained Z-value in the preposttest analyses were significantly favoring the posttest results. These remarkably high gains obtained by the subjects in the posttest can be attributed to the effect of using the suggested specific course.

Students' level in translation skills improved in general, however what deserves to be mentioned is that students' achievement in the first and third items of the test was higher than their achievement in the second and the fourth items. This is simply due to the lack of students' knowledge about the cultural items included in the short texts. They faced some kind of difficulty in finding appropriate equivalents for them. They used different strategies but they could not give the correct counterparts in the target language. This also reflected how strategies could be insufficient if students did do have enough knowledge about different cultures. Agood translator should be bicultural as well as bilingual.

Results also show the importance of implementing translation theoretical concepts in practical translation training as indicated by Thomas (1992), Gutt (2000), and Teleiba (2004). Students stated that they liked this specific translation course, that they started to recognize the importance and necessity of translation in their university life as well as in their future life. They wished they could have a similar specific course for different translation courses. They admired the systematic way in which the course was designed and taught; the objectives were clear, the tasks was purposeful, the strategies were applicable and the topics were varied.

Finally, results of the study clearly pinpointed that careful planning for the translation classes and systemic training in translation skills could contribute significantly to the improvement of students' ability to translate. Moreover, Students' success in performing the translation tasks correctly enhances their ability to translate and creates more favorable attitudes towards translation courses. On the other hand, the present study and the suggested specific course helped in motivating students to improve their translation skills, but they need more than just one specific course. There should be a holistic and interrelated web of language courses that run along the four years of study in order to achieve remarkable and considerable improvements in translation skills. In this study, because of time limitation, the sample was small. So, for the generalization of these findings and for higher reliability of the results more studies are needed. In general, based the research in translating culture-specific items, students should try to use equivalents as much as possible to give optimal translation, and in those cases which there are not any equivalent for them in the target language, they can convey all aspects of their meaning by translating them literally plus adding some note or create equivalent for them based on the target language word formation processes, or they can make new words in the target language by different means either to use the existing material in the target language in other new ways to increase its term formation processes or to import words from another language to enrich its vocabulary.

\section{CONCLUSION}

Since the twentieth century has been called the age of translation, translators, like all professionals, must undergo permanent training since their capacity is not measured in terms of pages, words or hours done, but rather the quality of the output or finished work. To reach that goal the present study tried to shed some light on the strategies that could be used to create and promote such quality through helping students have a chance to recognize these strategies in the classroom to use them later when they become future translators.

Teaching translation is not an easy job as most universities are not accustomed to give systematic specific courses that are based on theories of translation. Teaching translation in classroom, as Delisle (1981) stated is considered an arduous job that mortifies teachers, puts them in a state of despair at times. (p.54) In order to be successful in teaching translation, lecturers need to merge the teaching techniques they may deem best for their students with those of teaching translation. Besides, it is a real problem since one has to teach translation skills, techniques, and doing translation practice within a limited time span so more concentration and attention should be made in the selection of the texts that should be translated and the assignments that have to be done at home. An organized plan of study could help achieve such a goal. 
One of the worst things that were noticed before and during designing this specific course was that the majority of students regard translation as a minor subject compared with poetry, the novel, or drama. Since the class does not have textbooks, or even handouts, they assume that there is nothing to study, and all they have to do is to learn vocabulary by heart and just attend and write down whatever translations the lecturer may dictate. This was one of the motives that encouraged the researcher to develop a specific course so as to be a source of motivation and interest to most students. Having students of different levels of knowledge, skills, and abilities required developing a specific course that worked for all of them. It covered their needs by exceeding the training requirements in terms of levels of basic skills and knowledge. Consequently, the researcher made some modifications on the content in order to make it acceptable by a large number of students. The course materials was modified to be appropriate to all of them because if not they will easily lose motivation. In such a case, learning will not occur.

No one can deny that being skillful in translation is a talent: either you have got it or you have not but we must not forget that good learning and teaching can play a vital and significant role in developing students' skills and in creating positive attitudes towards translation. This was evident in the development of students' skills in translating culturespecific items and in doing their assignments actively and accurately. The present study concluded that translation is teachable because it is a craft and consequently teachable as are other crafts.

As far as designing a translation course is concerned, the present study found that it has to be designed in such a way that students who take this course will practice translating as much as possible. It must aim, at least, at developing the student's insight into the nature and significance of translation as such, as a result of the confrontation between the mother tongue and the foreign language while searching for equivalence in meaning and broadening the student's competence in the mother tongue and the foreign language. Students were encouraged to find the solutions of any translation problems themselves through showing them the right strategies that could be used to solve these problems. Students were shown how to apply the new strategies they were taught through translating authentic texts that include cultural topics. In the light of the study findings, it could be concluded that EFL students' performance in translating culture-specific items was acceptable as reflected by their scores on the culture-based translation test (CBTT).

\section{RECOMMENDATIONS}

It is recommended that to suggest a training program to familiarize university students with translation strategies. More research is needed to investigate students' ability to translate proverbs and figurative language. More research is needed to investigate students' ability to translate literary texts since culture represent a core component in literature.

Finally, it is hoped that the present study provided some insight into the issues surrounding the teaching students in the classroom to be translators. Accordingly, it reached the following recommendations:

1- Teachers of translation in the classroom should encourage the students to frequently use the dictionaries.

2- Students should deal with various topics on culture and religion. This procedure helps the students to have more practice in the different kinds of material and styles.

3- The course should focus on the development of the students' vocabulary more than of grammar, because the former is already a more problematic language component.

4- The course should deal with expressions, phrases and topics of different levels of difficulty according to the students' abilities. There should be clear cut, and agreed-upon standards for designing translation courses, translation activities, translation tests, and even for determining who is the translation instructor.

5- There should be a balance between practice and theory, with very little theoretical guidelines. That is to say, translation theory should be integrated in translation courses in the form of graded activities that are related to the practical translation skills presented in each course.

\section{AppendiX A. Culture-Based Translation Test (CBTT)}

Dear Students:

The researcher designed such a test in order to investigate the effectiveness of strategy-based course in developing students' skills in translating culture- specific terms from Arabic into English and vice versa at Al Imam Muhammad bin Saud Islamic University, College of Languages and Translation. The researcher studies the difficulties and problems that the students face during the translation process from English into Arabic and vice versa.

(A) Personal Information:

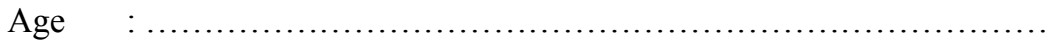

Level

Degree in Last Translation Course:

You are kindly requested to answer the test seriously

(B) The Test

I. Give the suitable cultural Arabic equivalent for the following expressions and decide on which strategy can be used to translate it accurately

1. As beautiful as a lark. 
2. To hit two birds with one stone.

3. To throw all man's cards

4. Kung Fu...

5. The white House

6. Love virus

7. Parkinson's disease

8. Cream tea

9. Catch 22 .

10. Tilbury...

II. Translate the following statements into Arabic and decide on which strategy can be used to translate it accurately:

(1) The one parent child association released its latest booklet which includes all the services it offers to its members.

(2) The Lee Marvin palimony case shows that married or unmarried people who live together cannot avoid a shared responsibility.

(3) According to the police, car boot sales are notorious places where stolen goods are sold.

(4) In the US, an organization called big brothers and sisters provides mentors for poor under-privileged and highrisk children.

(5) Unless I got it from the horse's mouth or had undeniable evidence, I would never say it's a fact that I know.

(6) The recently introduced New Tradition Axminster range is already creating great interest and will be on display at the exhibition.

(7) Many love children suffer from psychological problems.

(8) The stock market goes under the control of fat cats.

(9) His political scandal is a real can of worms. Let's not open that again.

(10) A lot of criminals also live in poverty, and I don't hear anyone screaming Shavian imprecations about that.

III. Give the suitable cultural English equivalent for the following expressions and decide which strategy can be used to translate it accurately
1. قيس وليلى.
2. انتفاضية.
3. كافر.
4. بيت الله الحرام الماءم .

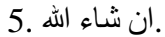
6. نعيما- أنعم الله عليكاه
7. القبلة.

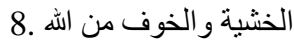
9.
10. فضل العطاء و السخاء.

(A) Translate the following statements into English and decide on which strategy can be used to translate it accurately:

$$
\text { ألقى السيناتور خطابا طنانا رنانا بعد الوليمة. }
$$


2. يحتاج المرء لصبر أيوب لانهاء هذا العمل

3. ان هبت رياحلك فاغتنمها

4. أتلجت الأخبار صدره

5كذا يصل الاستبداد الى أقصى حدوده, هكذا يصفع العالم على قفاه ممثلا في منظماته التي أنشأها لحماية ومناصرة الاقوياء .

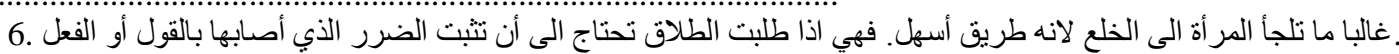

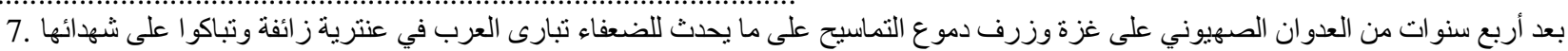

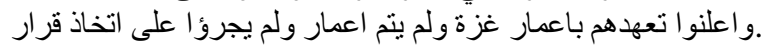

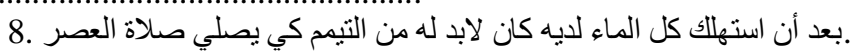

9. لقد اعتكف جارى في المسجد لمدة عثرة أيام في رمضان الماضي.

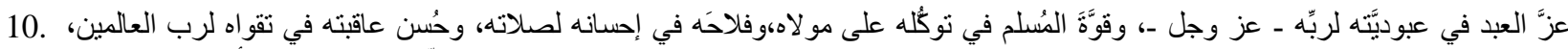

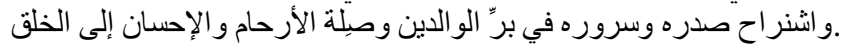

\section{REFERENCES}

[1] Al-Hasnawi, Ali. (2007). A Cognitive Approach to Translating Metaphors. Translation Journal 11(3). Retrieved on 1st Jun 2007 from: http://translationjournal.net/journal/41 culture.htm.

[2] Al Maghreby, F. A. (1995). "Towards a Communicative Use of Translation in a Global Age". English Language In 2000, Proceedings of the CDELT 14th National Symposium on English Language Teaching April 9-11, 1994, Cairo: Ain Shams University.

[3] Alousque, Isabel Negro. (2009). Cultural Domains: Translation Problems, Revista de Lingüística y Lenguas Aplicadas. volumen 4 año 2009.

[4] Aly, Abdul-Sadeq. (1990). A Suggested Course in Translation for the Students of English Language Sections in Faculties of Education in Egypt. Unpublished Ph. D. Thesis, Faculty of Education, Benha.

[5] Armellino, Elisa. (2008). Translating Culture-Bound Elements in Subtitling: An Example of Interlinguistic Analysis: a Scene from 'Scent of a Woman'. Translation Journal.12/2. Retrieved on 1st May 2008 from: http://translationjournal.net/journal/44culturebound.htm.

[6] Bahameed, Adel. (2008). Hindrances in Arabic-English Intercultural Translation. Translation Journal. 12(1). Retrieved on 19th May 2007 from: http://translationjournal. net/ journal/43culture.htm.

[7] Chau, S. C. (1984). "How to translate this is a red rose", in W. Wills \& G. Thome (eds): Translation Theory and Its Implementation in the Teaching of Translation and Interpretation. Tubingen: Gunter Narr; pp. 124-135.

[8] Dadour, A. (2004). A proposed Program for Developing EFL Prospective Teachers' Bicultural Awareness and their Performance in Translation: An Experimental Study. CDELT Occasional Papers. Vol. 38. Cairo: CEDLT, Ain Shams University.

[9] Gerding-Salas. C. (2000)."Teaching Translation, Problems and Solutions". Translation Journal Online.Vol4, No3. July 2000 Available: http:// accurapid. com/journal.

[10] Gutt. E. (2000). 'Translation as Interlingual Interpretive Use'. In Lawrence Venuti (ed). The Translation Studies Reader. London: Routledge.

[11] Hariyanto, Sugeng. (1997). An Evaluation of the English Translation of An Indonesian Novel: A Case Study on the Translation. Unpublished Project, SEAMEO RELC Singapore.

[12] Harvey, M. (2003). A beginner's Curse in Legal Translation: The Case of Culture Bound Terms. Retrieved on 17th May 2007 from: http://www.tradulex.org/Actes2000/harvey.pdf.

[13] Hermans, Theo. (1999). Translation in Systems: Descriptive and System-Oriented Approaches Explained. Manchester: St. Jerome.

[14] Larson, M. L. (1984). Meaning-Based Translation: A Guide to Cross-language Equivalence. Larham: University Press of America.

[15] Lefevere. A. (1992). Translation/History/Culture London: Routledge. 
[16] Lorscher, Wolfgang. (1991). Translation Performance, Translation Process, and Translation Strategies: A Psycholinguistic Investigation. Tubingen, Germany: Gunter Narr Verlag.

[17] Newmark, Peter. (2001). Translation and Culture. In Translation and Meaning: Part 5. Thelen, Marcel and Lewandowska editors. Maaastricht School of Translation and Interpreting. Poland. Pp. 327-334.

[18] Newmark, Peter. (1988). Approaches to Translation. Hertfordshire: Prentice Hall.

[19] Nida, Eugene. A. (1964). Towards a Science of Translation, with Special Reference to Principles and Procedures Involved in Bible Translating. Leiden: Brill.

[20] Nida, Eugene. A. (2001). Contexts in Translating. Amsterdam: John Benjamins.

[21] Pena, Elizabeth. (2007). Lost in Translation: Methodological Considerations in Cross-Cultural Research. Child Development. 78 (4). 1255-1264.

[22] Rabin, C. (1972). Cultural aspects of bible translation" in Babel vol. 18, No. 3; pp. 11-19.

[23] Samudra, J. (1993). Proposed Guidelines for Translation Instructors of the Sarjana Program at English Departments. Tubingen, Germany: Gunter Narr Verlag.

[24] Seguinot. C. (1991). A Study of student translation strategies. In Tikkonen-Condit (ed.). Empirical Research in Translation and Intercultural Studies. Tubingen: Narr.

[25] Teleiba, Antar Solhy Abdellah. (2002). Towards a Systematic Translation Course Design in Arab Universities. Proceeding of 22nd CEDLT National Symposium. Cairo: CEDLT, Ain Shams University.

[26] Teleiba, Antar Solhy Abdellah. (2004). A Suggested Program for Developing Some Basic Translation Skills of English Majors and its Effect on their Attitudes towards Translation, PhD Thesis, South Valley University, Qena Faculty of Education.

[27] Thomas. S. (1992). The Implication of Translation Theories for Language Teaching Pedagogy. PhD Thesis, Institute of Education. University of London.

[28] Valette, R. (1986) "The culture test" in M. Valdes (ed): Culture Bound, Bridging the Cultural Gap in Language Teaching. Cambridge: Cambridge University Press.

[29] Zare-Behtash, Esmail. (2010). Culture-Specific Items in Literary Translations, Translation Journal. Vol.14.No.1, January, From http://translationjournal.net/journal/00toc.htm.

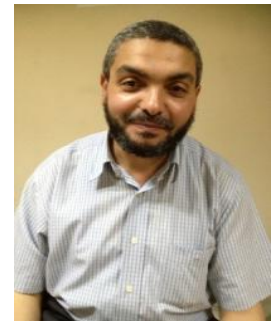

Montasser Mohamed AbdelWahab Mahmoud, Ph.D in TEFL, An Assistant Professor at Al-Imam Muhammad bin Saud Islamic University, College of Languages and Translation, Riyadh, Saudi Arabia, A Lecturer at Al-M'aref Higher Institute of Languages and Translation, Cairo Egypt, A reviewer at the International Education Studies, Canadian Center of Science and Education till May 2015, A Translator and Editor at Al-Harmain Translation Project. 